\title{
EFEITO DO PACLOBUTRAZOL E DE ÁCIDO GIBERÉLICO NA INDUÇÃO FLORAL DO MARACUJAZEIRO-AMARELO EM CONDIÇÕES DE ENTRESSAFRA ${ }^{1}$
}

\author{
ELMA MACHADO ATAÍDE ${ }^{2}$, CARLOS RUGGIERO ${ }^{3}$, JOÃO CARLOS DE OLIVEIRA ${ }^{4}$, \\ JOÃO DOMINGOS RODRIGUES ${ }^{5}$, HÉRCULES JOSÉ DE OLIVEIRA ${ }^{6}$
}

\begin{abstract}
RESUMO - Objetivou-se estudar os efeitos de ácido giberélico ( $\mathrm{GA}_{3}$ ) (i.a.), nas concentrações de 50 e $100 \mathrm{mg} \mathrm{L}^{-1}$, acrescido do espalhante adesivo Extravon ${ }^{\circledR}$ a $0,05 \%$, em duas aplicações via foliar e do paclobutrazol (PBZ) (i.a.), em doses de 2 e $4 \mathrm{~g}$ por planta, aplicado via solo, em uma única aplicação, na antecipação da floração do maracujazeiro-amarelo, em Araguari-MG. O delineamento experimental empregado foi em parcelas subdivididas, com cinco tratamentos (parcelas) e dois tratamentos (subparcelas), com quatro repetições e quatro plantas por parcela. Foram identificados 12 ramos terciários por parcela, com seis ramos expostos à luminosidade predominante pela manhã e seis com luminosidade predominante à tarde. Avaliaram-se os dois lados da espaldeira aos 103 dias após a primeira aplicação dos tratamentos, observando-se o comprimento dos ramos e de entrenós, número de nós e de botões florais. Os reguladores não promoveram respostas significativas para o comprimento dos entrenós e o número de botões florais. Porém, observaram-se indícios de maior número de botões florais com PBZ $2 \mathrm{~g}$. O maior comprimento dos ramos foi obtido com $\mathrm{GA}_{3} 100 \mathrm{mg} \mathrm{L}^{-1}$, sob luminosidade, pela manhã. Ao se compararem os tratamentos nas duas condições de luminosidade, o PBZ $4 \mathrm{~g}$, independentemente da condição de luminosidade, proporcionou o menor comprimento dos ramos.
\end{abstract}

Termos para Indexação: Passiflora edulis f. flavicarpa, regulador vegetal, floração.

\section{EFFECT OF PACLOBUTRAZOL AND GIBBERELLIC ACID IN FLORAL INDUCTION OF YELLOW PASSION-FRUIT IN INTERCROP CONDITION}

\begin{abstract}
The present study objective was to evaluate gibberellic acid (GA $)$ (a.i.), in the concentrations of 50 and $100 \mathrm{mg} \mathrm{L}^{-1}$, increased by the Extravon ${ }^{\mathrm{TM}}(0.05 \%)$ adhesive spreader in two leaf applications, and the use of paclobutrazol (PBZ) (a.i.), with dosages of 2 and $4 \mathrm{~g}$ per plant, and a single application on the soil at yellow passion-fruit flowering anticipation in Araguari-MG. The experimental design was in split-plots with five treatments (plots) and two treatments (subplots), with four repetitions and four plants per plot. Twelve tertiary branches were identified per plot, with six branches exposed to predominantly morning brightness and six exposed to predominantly evening brightness. Both sides were evaluated at 103 days after the first treatment application, whereas the length of the branches and the internodes, number of nodes and number of floral buds were observed. The regulators did not promote significant responses for internodes length and floral buds number. However, an indication of a greate number of flower buds was observed with $2 \mathrm{~g}$ of PBZ. The larger length of branches was obtained with $100 \mathrm{mg} \mathrm{L}^{-1} \mathrm{of} \mathrm{GA}_{3}$ and under the morning brightness. Comparing the treatments from both brightness conditions, $4 \mathrm{~g}$ of $\mathrm{PBZ}$ offered the smallest branch size independently of the luminosity condition.
\end{abstract}

Index terms: Passiflora edulis f. flavicarpa, plant regulator, flowering.

\section{INTRODUÇÃO}

No Brasil, o maracujazeiro-amarelo é cultivado em diferentes condições climáticas, desde regiões quentes dos trópicos até as de clima subtropical. Nestas distintas regiões, as plantas apresentam comportamento florífero diferente durante o ano, devido à indução à floração, com conseqüente variações significativas nas produções e períodos de colheita. Assim, os preços praticados no CEAGESP-SP, pelo maracujá in natura, sofrem grandes variações durante o ano, chegando a alcançar, em média nos últimos quatro anos, $\mathrm{R} \$ 1,06$ a $1,19 / \mathrm{kg}$ na entressafra (setembro a novembro), em relação à época da safra (dezembro a agosto), cujos preços variam de $\mathrm{R} \$ 0,60$ a $0,96 / \mathrm{kg}$ (Agrianual, 2005). Dessa forma, constitui-se uma excelente opção de mercado a produção de frutos para colheita na entressafra, o que tem motivado o plantio na região Norte e Nordeste do Brasil, onde o maracujazeiro floresce o ano todo.

De acordo com Menzel \& Simpson (1994), a sazonalidade da produção em maracujazeiro é influenciada pelos fatores externos: comprimento do dia, temperatura, radiação solar e precipitação. De acordo com Larcher (2000), esses fatores atuam, principalmente, em conjunto com a regulação de mecanismos endógenos.

Segundo Watson \& Bowers (1965), o maracujazeiro é exigente em luminosidade, florescendo quando submetido a 12 ou mais horas de luz, fato esse observado nas diferentes regiões produtoras de maracujá do País. Nas condições do Sudeste do Brasil, as baixas temperaturas e o comprimento do dia inferiores a 11 horas, no outono e inverno, têm sido limitantes à produção na entressafra (Ruggiero et al., 1996).

Na região Sul, a influência do fotoperíodo é mais acentuada, enquanto no Nordeste, precisamente na Bahia, encontram-se três condições distintas: a) o semi-árido, não havendo limitação por água, o florescimento é contínuo durante o ano, com produção na entressafra da região Sudeste, ocorrendo o mesmo na região Norte do País; b) a zona litorânea, desde o recôncavo até o extremo sul, onde as plantas não florescem nos meses de julho e agosto (Ataíde et al., 2003); c) e as regiões com altitudes elevadas, onde se observa a floração o ano todo, porém os botões florais não se fixam no período de inverno (junho e julho).

Os sinais de desenvolvimento que resultam na indução floral, são também influenciados por fatores endógenos, tais como o ritmo circadiano, a mudança de fase e os hormônios. As interações entre os fatores endógenos e exógenos capacitam a planta a sincronizar seu desenvolvimento reprodutivo com o ambiente (Taiz \& Zeiger, 2004). Possivelmente, baixos níveis de hormônios (balanço hormonal) podem ser supridos com aplicação exógena de reguladores vegetais. Dentre os principais grupos, com possibilidade de uso exógeno, estão as

\footnotetext{
(Trabalho 197-2005). Recebido: 01-12-2005. Aceito para publicação: 25-05-2006. Parte da tese da primeira autora, para obtenção do título de Doutora em Agronomia (Produção Vegetal) na FCAV/UNESP.

${ }^{2}$ Dra. Departamento de Produção Vegetal da FCAV-UNESP. Via de acesso Prof. Paulo Donato Castellane, s/n, CEP 14884-900, Jaboticabal-SP E-mail: elmaataide@yahoo.com.br.

${ }_{3}^{3}$ Dr. Prof. Titular do Departamento de Produção Vegetal da FCAV-UNESP. E-mail: ruggiero@fcav.unesp.br.

${ }^{4}$ Dr. Prof. Titular do Departamento de Botânica, Instituto de Biociências-UNESP-Botucatu. E-mail: mingo@ibb.unesp.br.

${ }^{5}$ Dr. Prof. Titular do Departamento de Produção Vegetal da FCAV-UNESP. E-mail: jcoliveira@fcav.unesp.br.

${ }^{6}$ Supervisor Agrícola da Kraft Foods Brasil S. A. Araguari-MG. E-mail: hercules.oliveira@fkraftla.com.
} 
auxinas, giberelinas, citocininas, etileno, retardadores e inibidores (Taiz \& Zeiger, 2004). Assim, é importante obterem-se informações técnicas sobre o uso exógeno de reguladores vegetais que possibilitem a antecipação da produção do maracujá-amarelo, especialmente na região Sudeste, pois representa uma opção para colheitas em épocas mais oportunas de mercado.

A utilização das giberelinas em frutíferas é diversa e tem sido aplicada em vários estádios fisiológicos das plantas: alongamento do caule e entrenós, na transição do estado juvenil para o maduro (Taiz $\&$ Zeiger, 2004). Em laranjeiras e limoeiros, a sua aplicação durante o período de formação e diferenciação floral é capaz de reduzir ou mesmo inibir o florescimento, na primavera (Monselise \& Haley, 1964). Em mangueiras, pode ser utilizada em várias situações, como para causar atraso na floração, permitindo o florescimento em época oportuna; para reverter a ação do paclobutrazol, que em doses elevadas pode causar redução no tamanho ou compactação das panículas florais; bem como para melhorar a qualidade de frutos. Da mesma forma, o Paclobutrazol® tem sido utilizado como retardador de crescimento vegetativo, com ação na altura da planta e no comprimento dos entrenós dos ramos (Manica, 1996). Segundo Fonseca (2002), quando o Paclobutrazol ${ }^{\circledR}$ é aplicado em doses elevadas na cultura da manga, pode ocorrer a compactação dos ramos novos, tendo como conseqüência a sobreposição das folhas. Esse composto tem como principal efeito bioquímico a supressão da síntese de giberelinas pela inibição da oxidação do caurene para o ácido caurenóico (Tongumpai et al., 1991).

O objetivo do trabalho foi avaliar os efeitos da aplicação do paclobutrazol e de $\mathrm{GA}_{3}$, sobre a floração do maracujazeiro-amarelo, em Araguari-MG, região com limitação fotoperiódica ao florescimento de maio a agosto.

\section{MATERIAL E MÉTODOS}

O experimento foi realizado em pomar de maracujazeiroamarelo seleção Maguari, com oito meses de idade, em Araguari-MG, no período de maio a setembro de 2001. O clima da região é tropical quente e úmido, seco no inverno. A área localiza-se em latitude $18^{\circ} 42^{\prime} 42^{\prime \prime}$ S e longitude $48^{\circ} 53^{\prime} 80^{\prime \prime}$ W e altitude de $889 \mathrm{~m}$, medidos com GPS. As temperaturas do período de maio a setembro de 2001 apresentam média extrema máxima de $39,6^{\circ} \mathrm{C}$ e extrema mínima de 14,3 ${ }^{\circ} \mathrm{C}$ e a média máxima de $25,8{ }^{\circ} \mathrm{C}$ e mínima de $11,4^{\circ} \mathrm{C}$. O fotoperíodo (horas) médio mínimo é de 10,92 (julho) e máximo, de 11,67 (setembro). As plantas foram conduzidas em espaldeira com um fio de arame a
$1,80 \mathrm{~m}$ do solo, com espaçamento $3,0 \times 5,0 \mathrm{~m}$, sob irrigação por gotejamento, observando o balanço hídrico da região. Os tratos culturais e adubações foram os convencionais para a cultura do maracujazeiro-amarelo na região.

O delineamento experimental foi em parcelas subdivididas, com cinco tratamentos principais (parcelas): $\mathrm{T}_{1}$ - Testemunha; $\mathrm{T}_{2}-50$ $\mathrm{mg} \mathrm{L}^{-1} \mathrm{de} \mathrm{GA}_{3} ; \mathrm{T}_{3}-100 \mathrm{mg} \mathrm{L}^{-1} \mathrm{de} \mathrm{GA}_{3}$, produto comercial Fitogib (i.a.), acrescidas de espalhante adesivo a $0,05 \%$, produto comercial Extravon ${ }^{\circledR}$; ambas em duas pulverizações foliares (07-05-01 e 12-0601); com pulverizador costal manual, com bico cônico; $\mathrm{T}_{4}-2 \mathrm{~g}$ de paclobutrazol, e $\mathrm{T}_{5}-4 \mathrm{~g}$ de paclobutrazol, produto comercial Pachlobutrazol ${ }^{\circledR}$, com $10 \%$ de i.a. por planta, aplicados via solo, em uma única aplicação (07-05-01). Além desses, foram utilizados dois tratamentos secundários (subparcelas): exposição dos ramos à luminosidade, predominante pela manhã e à tarde, com quatro repetições. Cada parcela foi constituída por seis plantas, com quatro plantas úteis. Cada subparcela foi um dos dois lados da espaldeira. Foram identificados 12 ramos terciários por parcela, sendo seis ramos para cada exposição de luminosidade, sendo avaliados o comprimento dos ramos e dos entrenós, número de nós e de botões florais, aos 103 dias após a primeira aplicação dos tratamentos.

A análise estatística foi feita considerando os tratamentos com reguladores vegetais nas parcelas e, nas subparcelas, as duas condições de luminosidade. As comparações entre as médias foram realizadas pelo teste de Tukey, a $5 \%$ de probabilidade.

\section{RESULTADOS E DISCUSSÃO}

Considerando as variáveis estudadas, verificou-se que o comprimento dos entrenós e o número de botões florais de maracujazeiro-amarelo não foram significativamente influenciados com o emprego dos reguladores vegetais. No entanto, verifica-se, na Tabela 1 , que, embora o número de botões florais não tenha apresentado significância estatística, observaram-se indícios de maior valor do número destes com paclobutrazol $2 \mathrm{~g}$.

Com relação aos resultados obtidos para o número de nós, verificou-se maior média para o número deste com $\mathrm{GA}_{3} 100 \mathrm{mg} \mathrm{L}^{-1}$, o que faz parte dos efeitos fisiológicos deste grupo hormonal, conforme reportam Taiz \& Zeiger (2004). O menor valor dessa variável foi obtido com emprego de $4 \mathrm{~g}$ de paclobutrazol, o que foi observado por Fonseca (2002), na cultura da manga. Tal resultado é confirmado por Tongumpai et al. (1991), que o principal efeito bioquímico desse produto é a supressão da formação de giberelinas pela inibição do

TABELA 1 - Comprimento dos ramos e dos entrenós, número de nós e de botões florais do maracujazeiro-amarelo, em função da aplicação de paclobutrazol e GA 3 e da exposição à luminosidade, aos 103 dias. Araguari-MG.

\begin{tabular}{|c|c|c|c|c|}
\hline Tratamentos & $\begin{array}{l}\text { Comprimento dos } \\
\operatorname{ramos}(\mathrm{cm})\end{array}$ & $\begin{array}{l}\text { Comprimento dos } \\
\text { entrenós }(\mathrm{cm})\end{array}$ & $\begin{array}{l}\text { Número } \\
\text { de nós }\end{array}$ & $\begin{array}{l}\text { Número de } \\
\text { botões florai }\end{array}$ \\
\hline Testemunha & $106,3 \mathrm{bc}$ & $5,4 \mathrm{a}$ & $16,2 \mathrm{~b}$ & $9,5 \mathrm{a}$ \\
\hline $\mathrm{GA}_{3} 50 \mathrm{mg} \mathrm{L}^{-1}$ & $99,4 \mathrm{bc}$ & $5,3 \mathrm{a}$ & $17,6 \mathrm{~b}$ & $8,4 \mathrm{a}$ \\
\hline $\mathrm{GA}_{3} 100 \mathrm{mg} \mathrm{L}^{-1}$ & $199,0 \mathrm{a}$ & $5,2 \mathrm{a}$ & $33,0 \mathrm{a}$ & $9,4 \mathrm{a}$ \\
\hline PBZ $2 \mathrm{~g}$ & $168,5 \mathrm{ab}$ & $6,0 \mathrm{a}$ & $23,7 \mathrm{~b}$ & $11,4 \mathrm{a}$ \\
\hline PBZ $4 \mathrm{~g}$ & $77,5 \mathrm{c}$ & $4,5 \mathrm{a}$ & $15,0 \mathrm{~b}$ & $8,4 \mathrm{a}$ \\
\hline Teste F & $8,35^{* *}$ & $1,50^{\mathrm{ns}}$ & $13,62^{* *}$ & $1,32^{\mathrm{ns}}$ \\
\hline DMS $(5 \%)$ & 79,97 & 1,96 & 9,10 & 4,72 \\
\hline Exposição dos ramos & $\begin{array}{l}\text { Comprimento dos } \\
\text { ramos }(\mathrm{cm})\end{array}$ & $\begin{array}{l}\text { Comprimento dos } \\
\text { entrenós }(\mathrm{cm})\end{array}$ & Número de nós & $\begin{array}{c}\text { Número de } \\
\text { botões florais }\end{array}$ \\
\hline Luminosidade Manhã & $137,5 \mathrm{~A}$ & $5,4 \mathrm{~A}$ & $21,4 \mathrm{~A}$ & $9,2 \mathrm{~A}$ \\
\hline Luminosidade Tarde & $122,8 \mathrm{~B}$ & $5,1 \mathrm{~A}$ & $20,8 \mathrm{~A}$ & $9,6 \mathrm{~A}$ \\
\hline Teste F & $5,49^{*}$ & $1,41^{\mathrm{ns}}$ & $0,31^{\mathrm{ns}}$ & $0,62^{\mathrm{ns}}$ \\
\hline DMS (5\%) & 13,37 & 0,49 & 2,50 & 1,00 \\
\hline Interação T x E & $3,62 *$ & $0,85^{\text {ns }}$ & $1,84^{\mathrm{ns}}$ & $2.10^{\mathrm{ns}}$ \\
\hline CV (\%) Parcelas & 38,53 & 23,29 & 27,02 & 31,42 \\
\hline CV (\%) Subparcelas & 15,26 & 13,73 & 17,58 & 15,93 \\
\hline
\end{tabular}

Médias seguidas pelas mesmas letras, minúscula ou maiúscula nas colunas, não diferem significativamente, pelo teste de Tukey, a 5\%. *significativo ao nível

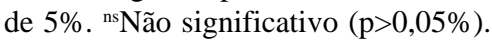


TABELA 2 - Comprimento dos ramos do maracujazeiro-amarelo, em função da interação dos tratamentos e da exposição dos ramos à luminosidade, aos 103 dias. Araguari-MG.

\begin{tabular}{ccc}
\hline Tratamentos & Luminosidade manhã & Luminosidade tarde \\
\hline Testemunha & $116,6 \mathrm{~A} \mathrm{bc}$ & $95,9 \mathrm{~A} \mathrm{~b}$ \\
$\mathrm{GA}_{3} 50 \mathrm{mg} \mathrm{L}^{-1}$ & $94,6 \mathrm{~A} \mathrm{c}$ & $104,1 \mathrm{~A} \mathrm{~b}$ \\
$\mathrm{GA}_{3} 100 \mathrm{mg} \mathrm{L}^{-1}$ & $202,6 \mathrm{~A} \mathrm{a}$ & $195,4 \mathrm{~A} \mathrm{a}$ \\
PBZ $2 \mathrm{~g}$ & $197,5 \mathrm{~A} \mathrm{ab}$ & $139,5 \mathrm{~B} \mathrm{ab}$ \\
PBZ $4 \mathrm{~g}$ & $76,1 \mathrm{~A} \mathrm{c}$ & $78,9 \mathrm{~A} \mathrm{~b}$ \\
\hline DMS (5\%) (linhas) & & 29,90 \\
DMS (5\%) (colUna) & & 83,35 \\
\hline
\end{tabular}

Médias seguidas pelas mesmas letras, maiúscula nas linhas e minúscula nas colunas, não diferem pelo teste de Tukey, a $5 \%$.

caureno para o ácido caurenóico.

As respostas em floração às aplicações exógenas de reguladores vegetais, em muitas espécies, são muito variáveis, como reportado por Etienne et al. (1993). Em parte, isso se deve aos fatores concernentes à aplicação, à absorção, ao transporte e metabolismo do produto.

A interação entre os tratamentos e a exposição dos ramos à luminosidade foram significativas para a variável comprimento dos ramos, em nível de 5\% de probabilidade (Tabela 1). Nas duas condições de luminosidade, verificou-se diferença significativa do comprimento dos ramos para o tratamento PBZ 2 g. O menor comprimento foi obtido em ramos expostos à luminosidade da tarde (Tabela 2).

Ao se compararem os tratamentos em condições de luminosidade pela manhã, verificou-se que o $\mathrm{GA}_{3} 50 \mathrm{mg} \mathrm{L}^{-1}$ e o PBZ 4 $\mathrm{g}$, apesar de não terem diferido da testemunha, apresentaram os menores valores para o comprimento dos ramos. No período de luminosidade à tarde, o PBZ $4 \mathrm{~g}, \mathrm{GA}_{3} 50 \mathrm{mg} \mathrm{L}^{-1}$ e a Testemunha apresentaram os menores comprimentos, sendo que não diferiram do PBZ 2 g. O maior comprimento foi obtido com GA $100 \mathrm{mg} \mathrm{L}^{-1}$, embora não diferindo do PBZ $2 \mathrm{~g}$.

Deve-se destacar que os resultados relacionados às condições de luminosidade podem ter sido influenciados pela localização das linhas da cultura, quando a maioria das lavouras tem sido implantada sem dar importância a esse efeito, como observado nesse experimento instalado no pomar comercial, onde as linhas das culturas estavam praticamente no sentido norte e sul. Esse resultado encontra respaldo em relato de Piza Júnior (1991), onde o mesmo reporta que, dada a sensibilidade ao fotoperíodo, a latitude e a face de exposição das espaldeiras desempenham importante função na produtividade, por influírem diretamente no período da floração. Por esta razão, deve-se evitar o plantio na face sul ou naquelas pouco ensolaradas no inverno.

Quanto ao efeito das aplicações exógenas de reguladores vegetais, de forma a estabelecer um balanço hormonal que favorecesse a floração do maracujazeiro, sob condições não indutivas (fotoperíodo inferior a 11 horas), que na região em estudo foi em junho e julho, não se observou o efeito significativo dos tratamentos. Observou-se a floração das plantas em junho (diferenciação das gemas em maio, fotoperíodo de 11,31 horas), enquanto, nos meses de julho e agosto, não floresceram (fotoperíodo inferior a 11 horas, nos meses que antecedem julho e agosto). Em trabalhos consultados para outras espécies, como reportado por Pereira-Netto (2002), a aplicação exógena supre as exigências de dias longos ou curtos, promovendo a floração, principalmente as de dias longos. Isso não foi observado nesse trabalho com o maracujazeiro-amarelo, sob condições de dias curtos. Porém, outros fatores podem ter influenciado no processo de diferenciação floral, tal como a temperatura, que, no período (junho), apresentou uma média de $18,5^{\circ} \mathrm{C}$, e média mínima de $15,0^{\circ} \mathrm{C}$, e extrema mínima de $10,0^{\circ} \mathrm{C}$. Essa observação encontra respaldo em relatos de Yamaguchi \& Kamiya (2000), que reportam que a temperatura pode alterar os níveis das giberelinas endógenas ativas.

A falta de conhecimento desses fatores, na maioria das vezes, leva a resultados contraditórios, como aqueles reportados nos diversos trabalhos. Assim, é importante realizar novos estudos, com uso de reguladores vegetais em maracujazeiro-amarelo, para melhor compreensão das relações entre os fatores externos e os níveis hormonais endógenos da planta, de forma a se obter controle da floração e, consequientemente, da época de produção.

\section{CONCLUSÕES}

1) Os reguladores vegetais não promoveram respostas significativas para o comprimento dos entrenós e o número de botões florais em maracujazeiro-amarelo, embora tenham apresentado indícios de aumento do número de botões florais com PBZ $2 \mathrm{~g}$.

2) $\mathrm{GA}_{3} 100 \mathrm{mg} \mathrm{L}^{-1}$ proporcionou o maior número de nós nos ramos.

3) O maior comprimento dos ramos foi obtido em condições de luminosidade pela manhã.

\section{AGRADECIMENTOS}

Os autores agradecem à Kraft Foods Brasil S. A. (MAGUARI) e à FRUTEZA sucos naturais Ltda., pelo suporte financeiro. À Empresa Agro Comercial Wiser Ltda., pela doação dos reguladores vegetais. Ao produtor Lourival, pela cessão da área, e ao José Rafael da Silva, do Viveiro Flora Brasil Ltda., pela colaboração na realização deste trabalho.

\section{REFERÊNCIAS}

AGRIANUAL 2005: anuário da agricultura brasileira. São Paulo: FNP, Consultoria \& AgroInformativos, 2004. p. 352-358.

ATAIIDE, E. M.; RUGGIERO, C.; SILVA, J. R. Uso de reguladores vegetais. In: SIMPÓSIO BRASILEIRO SOBRE A CULTURADO MARACUJAZEIRO, 6., 2003, Goytacazes, RJ. Anais... Goytacazes: UENF, 2003, CD-ROM.

ETIENE, H.; SOTTA, B.; MONTORO, P.; MIGINIAC, E.; CARRON, M. P. Relations between exogenous growth regulators and endogenous índole- 3 acetic acid and abscisic acid in the expression of somatic embriogenesis in Hevea brasiliensis (Muell. Arg.). Plant Science, London, v. 88, p. 91-96, 1993.

FONSECA, N. Paclobutrazol e estresse hídrico no florescimento e produção da mangueira (Mangifera indica L.) 'Tommy Atkins'. 2002. 134f. Tese (Doutorado em Agronomia) -Universidade Federal de Lavras, Lavras-MG, 2002.

LARCHER, W. Ecofisiologia vegetal. São Carlos: Ed. RiMa, 2000. 547p. MANICA, I. Indução do florescimento em mangueira. In: SÃO JOSÉ, A. R.; SOUZA, I. V. B.;

MARTINS FILHO, J.; MORAIS, O. M. (Coord.). Manga: tecnologia de produção e mercado. Vitória da Conquista-BA: UESB/DFZ, 1996. p. 140-144.

MENZEL, C. M.; SIMPSON, D. R. Passionfruit. In: SCHAFFER, B.; ANDERSEN, P. C. (Ed.). Handbook of enviromental physiology of fruit crops. Boca Raton: CRC Press, 1994. v. 2, p. 225-241.

MONSELISE, S. P.; HALEVY, A. H. Chemical inhibition and promotion 
of citrus flower bud induction. Journal of the American Society for Horticultural Science, Alexandria, v. 84, p. 141-146, 1964.

PEREIRA-NETTO, A. B. Crescimento e desenvolvimento. In: WACHOWICZ, C. M.; CARVALHO, R. I. N. (Org.). Fisiologia vegetal: produção pós-colheita. Curitiba: Champagnat, 2002. p. $17-41$.

PIZA JÚNIOR, C. A cultura do maracujá. São Paulo: CATI, 1991. 71p. RUGGIERO, C.; SÃO JOSÉ, A. R.; VOLPE, C. A.; OLIVEIRA, J. C.; DURIGAN, J. F.; BAUMGARTNER, J. G.; SILVA, J. R.; NAKAMURA, K.; FERREIRA, M. E.; KAVATI, R.; PEREIRA, V. Maracujá para exportação: aspectos técnicos da produção. Brasília: EMBRAPA, 1996. 64p. (FRUPEX).
TAIZ, L.; ZEIGER, E. Fisiologia vegetal. 3. ed. Porto Alegre: Artmed, 2004.719p.

TONGUMPAI, P.; JUTAMANEE, K.; SUBHADRABANDHU, S. Effect of paclobutrazol on flowering of mango cv. Khiew Sawoey. Acta Horticulturae, The Hague, n. 291, p. 67-70, 1991.

WATSON, D. P.; BOWERS, F. A.I. Long days produce flowers on passion fruit. Hawai Farm Science, Honolulu, v. 14, n. 2, p. 3-5, 1965.

YAMAGUCHI, S.; KAMIYA, Y. Gibberellin biosynthesis: its regulation by endogenous and environmental signals. Plant Cell Physiology, Kyoto, v. 41, n. 3, p. 251-257, 2000. 